\title{
Community pharmacists' interventions with electronic prescriptions in England: an exploratory study
}

\author{
Bryony Dean Franklin • Matthew James Reynolds • \\ Ralph Hibberd · Stacey Sadler • Nick Barber
}

Received: 15 January 2013/ Accepted: 12 September 2013/Published online: 28 September 2013

(C) Koninklijke Nederlandse Maatschappij ter bevordering der Pharmacie 2013

\begin{abstract}
Background Prescribing errors in primary care are problematic. The electronic prescription service (EPS) is an English electronic system linking prescribing, dispensing and reimbursement, designed to rectify some of the problems associated with paper-based prescribing. Objective To document the numbers and types of interventions made by community pharmacists and their staff using EPS release 2 (EPSR2), compare these with those made for other prescription types, and comment on potential effects of EPSR2 on pharmacy practice. Methods We invited staff in 15 community pharmacies to record problems encountered arising from failures in prescribing, dispensing or supply systems for prescribed medication, for a 2 week period. Results Eight pharmacies participated, of which five used EPSR2. These pharmacies reported 69 problems with 68 prescriptions (median 7.5 problems per pharmacy, range 2-22). A total of 33 problems were clinical in nature and 6 were organisational or logistical in origin. Thirty unsigned prescriptions were reported, all non-EPSR2. Of the 69 problems, eight were primarily related to EPSR2 functionality. Conclusion EPSR2 should reduce the number of unsigned prescriptions in circulation. However,
\end{abstract}

B. D. Franklin · M. J. Reynolds $(\bowtie)$

Pharmacy Department, Ground Floor, Charing Cross Hospital, Fulham Palace Road, London W6 8RF, UK

e-mail: Matthew.reynolds@imperial.nhs.uk

B. D. Franklin · R. Hibberd · N. Barber

Department of Practice and Policy, UCL School of Pharmacy,

Mezzanine Floor, Entrance A, BMA House, Tavistock Square,

London WC1H 9JP, UK

S. Sadler

NHS Rushcliffe Clinical Commissioning Group, Easthorpe

House, 165 Loughborough Road, Ruddington, Nottingham

NG11 6LQ, UK prescribers should avoid the use of Latin abbreviations that cannot be interpreted directly by patients, and consider the compatibility of regularly prescribed items with the NHS dictionary of medicines and devices.

Keywords Community pharmacy $\cdot$ Electronic prescribing · Pharmacists' interventions · Prescribing errors · United Kingdom

\section{Impact of findings on practice}

- To reduce the numbers of unsigned prescriptions in the UK, NHS prescribers in England should use the electronic prescription service release 2 (EPSR2) where appropriate.

- The creation of split prescriptions, where some items are prescribed electronically and some on paper, may cause problems; a method of highlighting prescriptions that are partly electronic and partly paper-based is needed.

- Since EPSR2 requires prescribed items to be compliant with the NHS dictionary of medicines and devices $(\mathrm{DM}+\mathrm{D})$, prescribers should change non-DM $+\mathrm{D}$ items to $\mathrm{DM}+\mathrm{D}$ equivalents wherever possible to avoid subsequent problems with EPSR2.

- Community pharmacy staff in the UK will need to check the directions on EPSR2 prescriptions before printing labels, and amend any that are not appropriately phrased for patients.

\section{Introduction}

Prescribing errors occur in $4.0 \%$ of drugs prescribed in United Kingdom (UK) primary care [1]. Community 
pharmacists play a key role in identifying and rectifying such errors, as well as resolving other problems such as unavailability of prescribed medication [2, 3]. However, previous UK studies have focussed on traditional paper prescriptions, either computer generated or handwritten [2, 3].

The introduction of England's electronic prescription service release 1 (EPSR1) for primary care began in 2005. EPSR1 prescriptions are standard paper prescriptions with an additional barcode. When the barcode is scanned in the community pharmacy, an electronic copy of the prescription data is downloaded to the pharmacy computer to populate the patient medication record and the labels for dispensed items.

EPS release 2 (EPSR2) is now being introduced, with the first sites having gone live in July 2009. EPSR2 is an electronic system linking prescribing, dispensing and reimbursement, designed to rectify some of the problems associated with paper-based prescribing such as unsigned prescriptions. Using EPSR2, electronic prescriptions are digitally signed by the prescriber and the electronic prescription transmitted to a nominated community pharmacy of the patient's choice. Patients are generally given a nonessential printed 'token' in lieu of a prescription, while the legal prescription is transmitted to the nominated pharmacy via a central server, the NHS 'Spine' [4]. A barcode on the token can be used to download the prescription at another pharmacy if required. Only items in the UK NHS dictionary of medicines and devices (DM + D [5]) can be prescribed using EPSR2, and schedule 2 and 3 controlled drugs cannot be prescribed.

No study has yet explored the types of prescribing errors identified or the interventions required by community pharmacists working with EPSR2. It is also not yet known whether EPSR2 will introduce new types of problems which community pharmacists will need to be aware of.

\section{Aim of the study}

We wanted to document the numbers and types of interventions made by community pharmacists working with EPSR2, compare these with those arising from non-EPSR2 prescriptions, and to comment on potential effects of EPSR2 on community pharmacy practice.

\section{Methods}

We invited all 15 community pharmacies, from five English primary care trusts, who were participating in a wider evaluation of the EPSR2 system and for whom we already had the appropriate permissions. At the time of data collection, nine (60\%) were using EPSR2 ('EPSR2 live'), and six $(40 \%)$ were not ('non-EPSR2 live'). As we were limited in the number of pharmacies we could approach and were asking pharmacy staff to record data, we incentivised participation by offering a $£ 100$ high-street voucher to participating pharmacy teams, supplied on completion.

We asked pharmacists to record information on all problems arising from failures in prescribing, dispensing or supply systems, in relation to prescribed medication, over a 2 week period. The feasibility of using such self-reported data in community pharmacy has previously been demonstrated [3, 6, 7]. We designed a data collection form for community pharmacy staff to complete, piloted this and then used the feedback to produce a final data collection booklet. This presented the study objectives, instructions for staff and 36 forms (Sect. Appendix). One of the research team briefed participating pharmacists on the project's purpose, how to complete the data collection booklet and addressed any queries; we asked pharmacists to brief locum pharmacists and other staff members as needed. We asked participants to record brief descriptions as soon as possible after identifying prescription-related problems that needed resolving to dispense the prescription, indicating how they were resolved, and whether the prescription was EPSR1, EPSR2, or non-EPS (either handwritten or computer generated). We also requested details of the number of items dispensed over the study period.

Data were analysed descriptively. We classified recorded problems in three ways. First, we categorised the type of problem into one of 13 mutually exclusive categories (Table 1). Second, the origin of the problem was categorised as being of a legal, clinical, or an organisational/logistical nature. Finally, any problems primarily related to EPS functionality were classified as being either EPSR1- or EPSR2specific. Each prescribed item could be associated with multiple problems. Classifications were discussed by the research team and agreed by consensus. Where we had data on the number of items dispensed during the study period, the prevalence of problems was calculated for each pharmacy.

This work was conducted as part of a larger evaluation of the EPSR2 system which was classed as a service evaluation; ethics approval was not required.

\section{Results}

Of the 15 pharmacies invited to participate, one provided only pilot data, and six did not return any data. Analysis was therefore based on eight $(53 \%)$ pharmacies, of which five were EPSR2-live (Table 2).

Staff in these eight pharmacies reported a total of 69 problems with 68 prescriptions over the 2 week study period (median 7.5 problems per pharmacy, range 2-22). Types 
Table 1 Interventions reported

\begin{tabular}{|c|c|c|c|c|c|c|c|}
\hline \multirow[t]{2}{*}{ Classification } & \multirow[t]{2}{*}{ Number $(\%)$ of problems } & \multicolumn{3}{|c|}{ Origin of problem } & \multicolumn{3}{|c|}{ Prescription type } \\
\hline & & Clinical & Legal & Organisational & Non-EPS & EPSR1 & EPSR2 \\
\hline Unsigned & $30(43 \%)$ & 0 & 30 & 0 & 19 & 11 & 0 \\
\hline Incomplete prescription & $6(9 \%)$ & 6 & 0 & 0 & 2 & 0 & 4 \\
\hline Missing prescription & $5(7 \%)$ & 2 & 0 & 3 & 2 & 1 & 2 \\
\hline Drug-drug interaction & $4(6 \%)$ & 4 & 0 & 0 & 3 & 1 & 0 \\
\hline Incorrect formulation & $4(6 \%)$ & 4 & 0 & 0 & 3 & 0 & 1 \\
\hline Incorrect drug & $4(6 \%)$ & 4 & 0 & 0 & 4 & 0 & 0 \\
\hline Incorrect quantity & $4(6 \%)$ & 4 & 0 & 0 & 3 & 1 & 0 \\
\hline Supply problem & $3(4 \%)$ & 0 & 0 & 3 & 0 & 1 & 2 \\
\hline Missing item & $2(3 \%)$ & 2 & 0 & 0 & 2 & 0 & 0 \\
\hline Incorrect dose & $2(3 \%)$ & 2 & 0 & 0 & 2 & 0 & 0 \\
\hline Duplicate drug & $2(3 \%)$ & 2 & 0 & 0 & 0 & 2 & 0 \\
\hline Incorrect instructions & $2(3 \%)$ & 2 & 0 & 0 & 1 & 0 & 1 \\
\hline Illegible prescription & $1(1 \%)$ & 1 & 0 & 0 & 1 & 0 & 0 \\
\hline Total ( $\%$ of all problems) & $69(100 \%)$ & $33(48 \%)$ & $30(43 \%)$ & $6(9 \%)$ & $42(61 \%)$ & $17(25 \%)$ & $10(14 \%)$ \\
\hline
\end{tabular}

Table 2 Details and workload of participating pharmacies

\begin{tabular}{lllllll}
\hline $\begin{array}{l}\text { Pharmacy } \\
\text { number }\end{array}$ & Location & $\begin{array}{l}\text { Number of days' } \\
\text { data collection }\end{array}$ & $\begin{array}{l}\text { Number non-EPS } \\
\text { dispensed items }\end{array}$ & $\begin{array}{l}\text { Number of EPSR1 } \\
\text { dispensed items }\end{array}$ & $\begin{array}{l}\text { Number of EPSR2 } \\
\text { dispensed items }\end{array}$ & $\begin{array}{l}\text { Total number of } \\
\text { items dispensed }\end{array}$ \\
\hline 37 & Village high street & 14 & 290 & 2,889 & Not EPSR2 live & 3,179 \\
38 & City-suburban & Not reported & Not reported & Not reported & Not EPSR2 live & 3,709 \\
39 & Town shopping centre & 14 & Not Reported & Not reported & Not EPSR2 live & 868 \\
46 & Inner city & 14 & 418 & 1,254 & 140 & 1,812 \\
48 & Inner city & 11 & 1,133 & 812 & 337 & 2,282 \\
49 & Town high street & 14 & Not reported & Not reported & Not reported & Not reported \\
50 & Town high street & 8 & Not reported & 606 & 311 & Not reported \\
51 & Inner city & 14 & Not reported & Not reported & Not reported & Not reported \\
\hline
\end{tabular}

of problem are shown in Table 1. In relation to the origin of each problem, $30(43 \%)$ were problems with the legal aspects of the prescription; these all related to unsigned non-EPS and EPSR1 prescriptions. A further 33 (48 \%) were clinical in nature. Potentially serious clinical errors included a prescription for an incorrect insulin pen (incorrect formulation) and a prescription for both erythromycin and simvastatin (drug-drug interaction). The remaining six $(9 \%)$ arose due to organisational or logistical problems. One, an EPSR1-specific problem, arose when a doctor mistakenly reprinted a copy of a previously dispensed prescription rather than creating a new one. Another two were EPSR2 prescriptions where the pharmacy had been incorrectly nominated. Manufacturing delays and prescription print-quality problems were also reported.

Five pharmacies reported the number of items dispensed during the study period, for these pharmacies the individual problem reporting rate ranged from 0.19 to $0.69 \%$ (1.9-6.9 problems per 1,000 items dispensed) giving an overall rate of $0.58 \%$ (69 problems in 11,850 dispensed items). The two EPSR2 live pharmacies reported 21 problems in 4,094 dispensed items $(0.51 \%)$, and three non-EPSR2 live pharmacies reported 31 problems in 7,756 items $(0.40 \%)$.

Overall, eight problems $(12 \%)$ were judged to have been caused specifically by the EPSR 2 system, and one (1\%) due to EPSR1. Specifically, we identified four cases, all at the same pharmacy, of incomplete EPSR2 prescriptions with no dose visible on the screen; the dose was printed on the dispensing token and therefore manually entered by the pharmacist. Some prescribers used Latin abbreviations, which we classed as 'incorrect instructions'. With EPSR2 these were transferred automatically to the dispensing label and had to be amended manually by pharmacy staff. For example "QDSPRN" had to be amended to "Four times a day when required". Two missing prescriptions were caused by community pharmacy nominations which had been incorrectly set up. The final problem involved a missing prescription: a patient 
arrived at the pharmacy having been told that their prescription had been transmitted electronically but the pharmacy staff had not received it. The GP surgery was called and it transpired that a paper prescription had in fact been issued, which was subsequently faxed to the pharmacy.

\section{Discussion}

The results of this study indicate that in line with previous work [3], circulation of unsigned paper prescriptions remains problematic, creating extra work for pharmacy and GP staff, as well as inconveniencing patients. EPSR2 prescriptions are digitally signed before transmission, thus eliminating this problem.

Problems specific to EPSR2 were also identified. One example of miscommunication resulted in a patient appearing at a pharmacy expecting an EPSR2 prescription, when their prescription was on paper and waiting at the GP surgery. This type of problem is likely to be problematic especially during EPSR2 roll-out, and may be exacerbated when a patient's medication is partly prescribed electronically and partly on paper (for example if any non DM + D items or controlled drugs are required). We also identified new problems caused by prescribers' instructions appearing automatically on the label directions. Traditionally, instructions on a prescription are interpreted and transcribed onto the medicine's label by pharmacy staff, using wording appropriate for the patient. The EPSR2 system can automatically transfer prescribers' dosage instructions onto the medication label without pharmacy staff actively entering them. The extra input needed by community pharmacy staff to manually edit prescribers' instructions may somewhat negate time savings envisaged through instructions being transferred automatically onto the label. Community pharmacies and their local GPs need to jointly establish common instruction templates for use on patient labels in order to fully realise the time-saving potential of EPSR2.

Our problem reporting rates are in line with similar studies $[3,8]$ but lower than that reported using more intensive data collection methods [9].

\section{Implications for practice}

Electronic prescription service release 2 (EPSR2) is likely to result in a decreased proportion of prescriptions arriving unsigned at community pharmacies, thus reducing unplanned workload for pharmacy and GP staff, and patient inconvenience. Problems were reported which were caused by prescribed items not being on DM $+\mathrm{D}$; steps should be taken to ensure that all items on EPSR2 are DM + D-compliant. The use of both paper and electronic prescriptions for the same patient has the potential to be problematic; a system which highlights the presence of additional non-EPSR2 prescriptions for EPSR2 patients should be investigated. GPs, pharmacists and software developers should work together to find solutions to problems such as the enduring use of abbreviations within an electronic system.

Strengths and limitations

This exploratory study is the first to look at problematic prescriptions in pharmacies using EPSR2. Limitations include the apparent mixed engagement of pharmacies in data collection which reduces the generalisability of the findings, and that only some pharmacies provided data on the number of dispensed items during the study period, limiting our ability to calculate problem prevalence rates; we suggest that future studies incorporate researchers periodically contacting participating pharmacies to increase engagement and to identify and resolve any barriers to ongoing participation. Future studies should establish the numbers of dispensed items, broken down by EPSR1, EPSR2 and non-EPS items, and use a larger sample size, in order to investigate differences in problem rates between the different types of prescription and whether other pharmacy-related factors and/or inter-pharmacist variability affect the problem rates documented. Finally, we did not formally assess the clinical significance of the problems identified.

\section{Conclusion}

Electronic prescription service release 2 (EPSR2) has the potential to reduce the number of unsigned prescriptions received at pharmacies. However, prescribers should avoid the use of Latin abbreviations that cannot be interpreted directly by the patients, and consider the compatibility of regularly prescribed items with DM $+\mathrm{D}$. Further work is needed to explore the causes of other types of problem identified and how they can be resolved before we can draw clear conclusions regarding the impact of EPSR2.

Acknowledgments We gratefully acknowledge all the community pharmacy staff involved in the project. We thank Tony Avery for his advice and support during the project and James Davies for assistance with data collection.

Funding This work forms part of independent research commissioned by the National Institute of Health Research. The views expressed in this publication are those of the authors and not necessarily those of the NHS, the National Institute for Health Research or the Department of Health. The CMSSQ is affiliated with the Centre for Patient Safety and Service Quality (CPSSQ) at Imperial College Healthcare NHS Trust which is funded by the National Institute of Health Research as a Patient Safety Translational Research Centre.

Conflicts of interest The authors have no conflicts of interest. 


\section{Appendix}

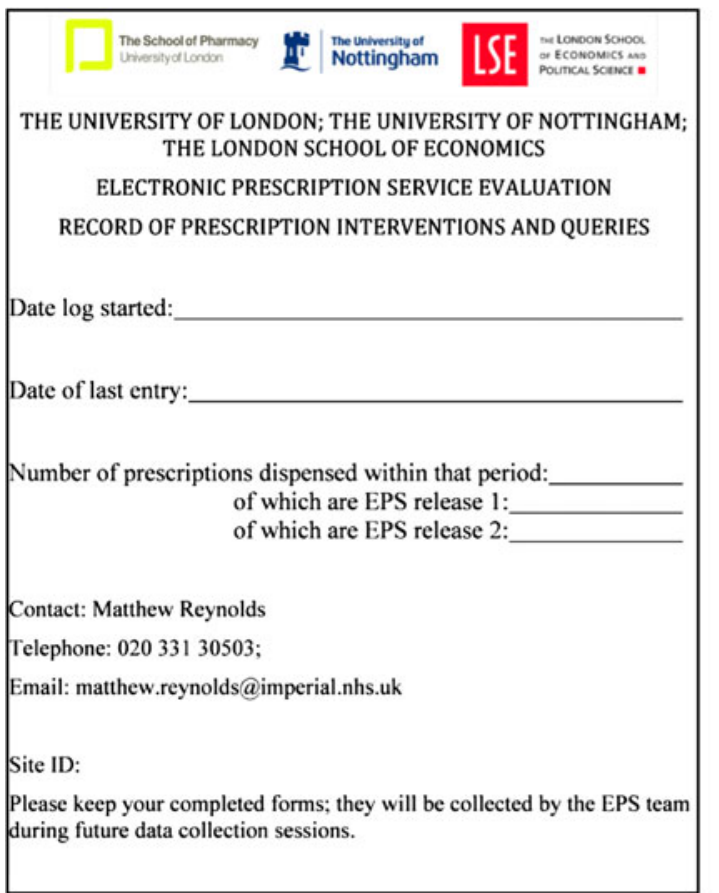

\begin{tabular}{|c|c|}
\hline Please include & Please exclude \\
\hline \multicolumn{2}{|c|}{ Prescription legality and validity problems } \\
\hline Unsigned / incomplete prescriptions & $\begin{array}{l}\text { Problems with extra requirements } \\
\text { of a controlled drugs prescription }\end{array}$ \\
\hline \multicolumn{2}{|l|}{ Unclear or ambiguous prescriptions } \\
\hline \multicolumn{2}{|l|}{ Out-of-date prescriptions } \\
\hline \multicolumn{2}{|l|}{ Forged prescriptions } \\
\hline \multicolumn{2}{|c|}{ Clinical queries } \\
\hline $\begin{array}{l}\text { Patient allergic to prescribed } \\
\text { medicine }\end{array}$ & Establishing medication review date \\
\hline $\begin{array}{l}\text { Establishing brand when clinically } \\
\text { relevant }\end{array}$ & $\begin{array}{l}\text { Establishing the brand of } \\
\text { medication preferred, when } \\
\text { clinically unimportant }\end{array}$ \\
\hline \multicolumn{2}{|l|}{$\begin{array}{l}\text { Clarifying a potentially significant } \\
\text { dosing or frequency query }\end{array}$} \\
\hline \multicolumn{2}{|l|}{$\begin{array}{l}\text { Correcting a prescription to } \\
\text { increase the probability of treatment } \\
\text { being timely and effective }\end{array}$} \\
\hline \multicolumn{2}{|l|}{$\begin{array}{l}\text { Establishing correct dosage form / } \\
\text { device }\end{array}$} \\
\hline \multicolumn{2}{|l|}{ Potentially significant interactions } \\
\hline \multicolumn{2}{|c|}{ Supply Queries } \\
\hline \multirow[t]{2}{*}{$\begin{array}{l}\text { Managing a lengthy ( }>1 \text { day) delay } \\
\text { caused by manufacturing or supply } \\
\text { problems, or discontinuation }\end{array}$} & $\begin{array}{l}\text { Informing patients when medicine is } \\
\text { out of stock but will be delivered } \\
\text { restocked within usual timescales }\end{array}$ \\
\hline & Supplying an emergency supply \\
\hline \multicolumn{2}{|c|}{ Patient preference queries } \\
\hline & $\begin{array}{c}\text { Establishing or amending flavour } \\
\text { preferences }\end{array}$ \\
\hline
\end{tabular}

\section{References}

1. Avery AJ, Barber N, Ghaleb M, Franklin BD, Armstrong S, Crowe $\mathrm{S}$, et al. Investigating the prevalence and causes of prescribing errors in general practice: The PRACtICe Study (PRevalence And

\section{Our aim:}

To detect the rates and types of prescription problems encountered by community pharmacies.

What are we interested in?

Detecting interventions, near-misses, and queries which you encounter on prescriptions presented to you.

What we would like you to do:

We would like you to record a brief description of each intervention or query, how you dealt with it and what the outcome was.

The situations we are interested in fall into four categories:

- Prescription legality and validity problems

- Clinical queries

- Supply queries

- Patient preferences

Please include or exclude situations in line with the examples on the opposite page.

What we would like you to record:

- what the problem or query was

- whether, and how, anyone else was contacted, e.g. GP

- what action you took

- what the outcome was

- whether this delayed the availability of the prescription

All information provided will remain anonymous. Thank you for your continued support.

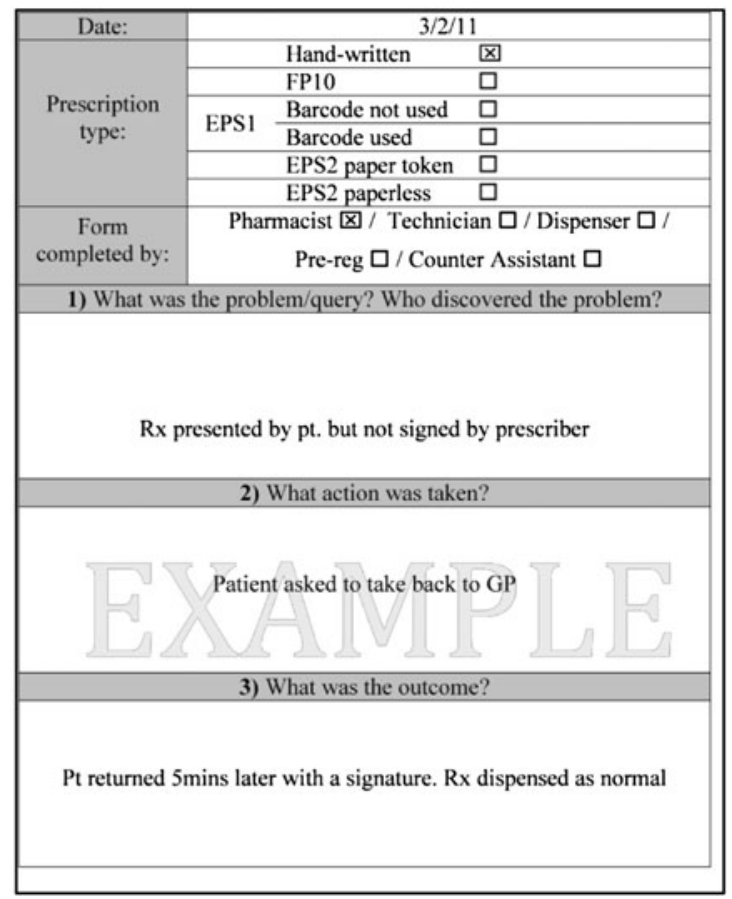

Causes of prescribing errors in general practiCe). A report for the GMC; 2012. p. 1-259.

2. Hawksworth GM, Corlett AJ, Wright DJ, Chrystyn H. Clinical pharmacy interventions by community pharmacists during the dispensing process. Br J Clin Pharmacol. 1999;47(6):695-700. 
3. Chen Y-F, Neil KE, Avery AJ, Dewey ME, Johnson C. Prescribing errors and other problems reported by community pharmacists. Ther Clin Risk Manag. 2005;1(4):333-42.

4. NHS Connecting for Health. Components of the electronic prescription service-NHS connecting for health [internet]. 2012. Available from: http://www.connectingforhealth.nhs.uk/ systemsandservices/eps/background/release2/how/components/ index_html. (last accessed 24 April 2013).

5. The NHS Dictionary of Medicines and Devices. Available from: http://www.dmd.nhs.uk/. (last accessed 24 April 2013).

6. Chua S-S, Wong ICK, Edmondson H, Allen C, Chow J, Peacham $\mathrm{J}$, et al. A feasibility study for recording of dispensing errors and near misses in four UK primary care pharmacies. Drug Saf. 2003;26(11):806-13.

7. Warner B, Gerrett D. Identification of medication errors through community pharmacies. Int J Pharm Pract. 2005;13:223-38.

8. Quinlan P, Ashcroft DM, Blenkinsopp A. Medication errors: a baseline survey of interventions recorded during the dispensing process in community pharmacies. Int J Pharm Pract. 2002; 10(suppl):R67.

9. Shah SNH, Aslam M, Avery AJ. A survey of prescription errors in general practice. Pharm J. 2001;267(December):860-3. 